http://dx.doi.org/10.5007/1980-3532.2013n9p23

\title{
Capitalismo, legalidade, direito e o cenário brasileiro na transição para o Pós-Fordismo
}

\section{Capitalism, legality, law and brazilian scene in the transition to Post-Fordism}

\author{
Leticia Galan Garducci \\ Mestranda em Direito Político e Econômico (MACKENZIE) \\ Graduanda em Ciências Sociais (USP) \\ lgarducci@gmail.com
}

\begin{abstract}
Resumo: O presente artigo busca melhor compreender a questão do direito e da legalidade no capitalismo, bem como a configuração destes elementos no contexto brasileiro de transição para o Pós-fordismo. Recorrese à Teoria da Derivação e, especialmente, à abordagem de autores derivacionistas que empreendem uma leitura das Escolas da Regulação, o que permite um entendimento pleno não só a estrutura do modo de produção capitalista, mas de seus diferentes cenários. Com isto é possível se alcançar uma compreensão ampla do direito e da legalidade, bem como de suas transformações, tais como as que se efetivaram no panorama brasileiro que será abordado.
\end{abstract}

Palavras-chave: Direito. Legalidade. Teoria da derivação. Brasil. Pós-fordismo.

Abstract: This article aims better understand the issue of law and legality in capitalism and the configuration of these elements in the Brazilian context of transition to post-Fordism. Drawing on Theory of Derivation, especially derivationists authors who do a reading of Schools Regulation, which allows fully understand not only the structure of the capitalist mode of production, but its different conjunctures. With this it is possible to achieve a broad understanding of law and legality, as well as their transformations, such as those that occurred in the Brazilian scenario that will be discussed.

Keywords: Law. Legality. Theory of derivation. Brazil. Post-fordism.

Originais recebidos em: 23/03/2014

Aceito para publicação em: 23/05/2014

\section{(1) $\Theta$}

Este trabalho está licenciado sob uma Licença Creative Commons Atribuição-Uso Não-

Comercial-Vedada a criação de obras derivadas 3.0 Unported License. 


\section{Introdução}

O capitalismo, ao mesmo tempo em que possui categorias estruturais que o conforma e lhe infringem estabilidade, contém elementos que se modificam com o seu desenrolar - desenvolvimento tecnológico, padrões de consumo, etc. - e que configuram seus diferentes cenários - liberalismo, fordismo, pós-fordismo. No presente artigo se buscará compreender como é que se apresenta o direito e a legalidade neste contexto de transformações próprias do capitalismo, examinando-se também como estes elementos se apresentam no caso do Brasil na passagem do fordismo para o pós-fordismo.

Referido recorte se justifica porque o exame do cenário brasileiro deste período se mostra bastante rico para uma melhor compreensão da questão do direito e da legalidade, na medida em que o país vivenciou significativas alterações no plano legal: de um regime de exceção jurídica vivido no período ditatorial, passou-se para a redemocratização em um regime de ampla legislação social, trazida especialmente pela Constituição Federal, e, após, para um período de contra ataque do mesmo com o avanço neoliberal, em um regime de exceção econômica calcado em um pretenso "estado de emergência”, conforme se analisará adiante.

Para empreender a esta análise, se recorrerá à Teoria da Derivação, privilegiandose a sua leitura que parte da tradição pachukaniana e, ainda, apropria-se de determinados conceitos da Escola da Regulação. Assim, se recorrerá à teóricos bastante relevantes para o pensamento crítico contemporâneo, como o cientista político Joachin Hirsch, da escola derivacionista alemã, e os jusfilósos brasileiros Alysson Leandro Mascaro e Camilo Onoda Caldas.

Por meio desta perspectiva teórica, será possível compreender não só os elementos estruturais que derivam e conformam o modo de produção capitalista, mas como é que se dão os diferentes cenários que se amoldam neste modo de relações sociais, tal como o pósFordismo, aonde se concentrará parte desta análise. A partir deste arcabouço teórico, portanto, se poderá melhor compreender como é que a legalidade e o direito se configuram em meio a estas mudanças.

Por fim, cabe apontar que a análise será divida em duas partes: na primeira se discorrerá acerca do direito e da legalidade no modo de produção capitalista, buscando-se 
compreender a própria gênese destes elementos neste modo de produção. Na segunda parte se examinará a configuração da legalidade e do direito no panorama brasileiro de transição para o pós-fordismo, a fim de se melhor entender como é que o país, neste período, passou de um regime de exceção jurídico para um regime de exceção econômico.

Com isto, pretende-se alcançar um melhor entendimento não só da configuração do direito e da legalidade no panorama brasileiro, mas os seus papéis e configurações no próprio modo de produção capitalista.

\section{Capitalismo, Legalidade e Direito}

Para se compreender o que é a legalidade e o direito, é preciso ter em mente o que é o próprio capitalismo, na medida em que necessariamente fazem parte do mesmo processo de relações sociais que conforma este modo de produção. Assim, neste primeiro momento, se verificarão quais são estas relações sociais das quais a legalidade e o direito são partes integrantes:

O capitalismo surge a partir de um processo de queda do modo de produção feudal, de renascimento do comércio, da formação dos burgos e do surgimento do Estado absolutista, que assegurava as relações comerciais. Neste momento a burguesia se tratava de uma classe nascente, e por isto precisava se encontrar aliada ao monarca que era quem detinha o poder político e econômico e assim garantia a segurança para o desenvolvimento das relações comerciais: "a burguesia, para a reprodução capitalista, necessitará de acordos e pactos com o Estado absolutista, de tal sorte que na dependência instável da política se assentarão as bases de uma reprodução que ainda não é autônoma” (MASCARO, 2008, p. 26).

Porém, com o desenvolvimento industrial e o fortalecimento da classe burguesa, se instaura um descontentamento crescente contra os privilégios nobiliárquicos. Estes se mostravam prejudiciais ao próprio desenvolvimento das relações mercantis, uma vez que a relação de dependência que a burguesia tinha com o monarca era mantida à base de concessões e desvantagem em relação aos nobres. Neste quadro é que irrompem as revoluções burguesas, momento em que esta classe ascende à posição de dominante e logra implantar um regime muito mais favorável à acumulação do capital: o governo das leis. 
Assim, é com a substituição do Estado absolutista pelo Estado de Direito que surge a legalidade e o próprio capitalismo. Bastante paradigmática deste quadro que se instaura é a Declaração dos Direitos do Homem e do Cidadão, fruto da Revolução Francesa em 1789 que, ao declarar "a lei é a expressão da vontade geral (...)" (artigo $6^{\circ}$ ), consagra a legalidade como princípio do Estado em um aparente manto de neutralidade.

Com esta passagem para o Estado de Direito, pela primeira vez o poder político deixa de estar concentrado nos agentes econômicos, sejam os senhores de escravo, os senhores feudais ou o próprio monarca - até porque foi somente quando se enfraqueceu o seu poder econômico e o da nobreza, em face do crescimento da classe burguesa, que o Ancien Régime chegou ao seu fim.

Esta dissociação do poder político e do poder econômico é o que coloca o Estado como forma específica deste modo de produção. Conforme aponta Caldas,

O Estado assume a forma de um poder público que arroga o monopólio da força. Ele não estará mais sobre o controle direto da classe dominante, pois assume o papel de garantir o respeito às leis e aos contratos, válidos igualmente para todos. Protegendo a legalidade, o Estado possibilita a reprodução do processo de exploração do trabalho e de acumulação do capital. (CALDAS, 2014, p. 18).

Porém, o capitalismo não representa somente o surgimento da legalidade e da forma política estatal. Conforme já destacou o jurista russo Evgenis Pachukanis, ainda no início do século XX, o modo de reprodução capitalista representa também o surgimento da forma jurídica, elemento específico e conformador do capitalismo.

E isto porque este modo de relações sociais, ao se fundar na exploração do indivíduo a partir do trabalho assalariado - e não mais a partir de domínio direto, como ocorria no escravagismo ou servilismo - necessita de que os indivíduos, na esfera pública, se mostrem livres e em relação de igualdade jurídica para que celebrem contratos de compra e venda, inclusive da própria força de trabalho, completando assim o circuito mercantil necessário à efetivação da mais valia ${ }^{1}$. Conforme ensina o professor Márcio Naves, maior estudioso do pensamento pachukaniano,

A forma-sujeito de que se reveste o homem surge como a condição de existência da liberdade e da igualdade que se faz necessária para que se constitua uma esfera geral de trocas mercantis e, consequentemente, para que se constitua a figura do proprietário privado desses bens, objeto de circulação. É na esfera da circulação

\footnotetext{
${ }^{1}$ Aqui, mais uma vez é interessante tomar como modelo a Declaração Universal dos Direitos do Homem e do Cidadão, que declara logo em seu artigo primeiro que "Os homens nascem e são livres e iguais em direitos. As distinções sociais só podem fundar-se na utilidade comum”.
}

Em Debat: Rev. Dig., ISSNe 1980-3532, Florianópolis, n. 9, p. 23-39, jan-jun, 2013. 
das mercadorias, como um elemento dela derivado que opera para tornar possível a troca mercantil, que nasce a forma jurídica do sujeito (NAVES, 2008, p. 65).

Assim, tem-se que os direitos de liberdade e igualdade necessários ao sujeito no capitalismo, somados a direitos como o da propriedade privada e do cumprimento dos contratos, representam o que se pode chamar de um núcleo mínimo fundamental que o Estado deve assegurar para a reprodução do capital. Portanto, quando se fala de governo das leis, há que se ter em mente que se trata do governo destas leis, ou seja, aquelas relativas à esfera civil - e não política, conforme será analisado ao final deste capítulo - e fundamentais à reprodução do sistema.

A respeito deste núcleo de direitos essenciais, também é interessante observar que

O direito somente pode ser compreendido como norma social, não como norma simplesmente. Liberdade, igualdade, propriedade privada, apresentam-se como direitos - como parte da lei -, mas não tiveram sua existência determinada simplesmente por uma decisão do Estado, pelo contrário, por serem os elementos da economia capitalista, se materializam nas relações sociais de classe e se tornaram objeto de reivindicações políticas da burguesia, que encontraram no poder do Estado soberano - centralizador da jurisdição - os meios para garantilos (CALDAS, 2014, p. 26).

Porém, embora o arcabouço jurídico sempre apresente direitos primordiais à reprodução capitalista, é certo que o conteúdo do aparato legal definido e defendido pelo Estado se modifica de tempos em tempos, podendo se encontrar de cunho mais social ou ainda mais explorador. E isto porque embora o capitalismo apresente um núcleo estável que o estrutura - qual seja, a forma mercadoria, a forma jurídica e a forma política estatal - este modo de produção é necessariamente portador de crises, o que provoca as transformações de cenários.

Estas crises, conforme já apontado por Marx, se apresentam como crises cíclicas, uma vez que são inerentes a este modo de produção em função das inúmeras contradições que apresenta (exploração de classe, lei da queda tendencial da taxa de lucro, etc.). Exemplo destas rupturas periódicas são as grandes depressões de 1870, 1930 e 1970.

E, tal como apontam os teóricos derivacionistas, a cada ruptura um novo panorama se apresenta devido a determinados elementos que se transformam com a formação de cada crise. Estas alterações, diferentemente das formas estruturais acima estudados, podem ser 
enquadradas como categorias intermediárias, e são identificadas em duas principais concepções: regime de acumulação e modo de regulação ${ }^{2}$.

O regime de acumulação se trata do "conjunto de regularidades que garante uma progressão geral e relativamente coerente da acumulação do capital" (BOYER, 2009, p. 81). Aqui se pode falar do capital invertido, da estrutura do aparelho produtivo conforme setores, das normas de produção, do consumo social, etc. (HIRSCH, 2010, p. 106). Ou seja, as condições econômicas que se apresentarem por determinado período capazes de promover a valorização do capital no processo de acumulação irão configurar um "regime de acumulação".

No entanto, estas condições no campo econômico não se encontram isoladas, ou independentes de demais circunstâncias. Um determinado regime de acumulação só alcança estabilidade por algum período se houver um modo de regulação correspondente, que lhe dê sustentação:

Para que haja a possibilidade de apropriação do resultado do trabalho de terceiros, recrutados mediante contrato, há formas sociais e uma série de mecanismos políticos e jurídicos que consolidam um núcleo institucional suficiente à própria acumulação. (...) Não só o que é explicitamente público entra nessa conta institucional, mas também uma rede vasta e estrutural que perpassa entidades, sindicatos, igrejas, escolas, família, cultura e meios de comunicação em massa (MASCARO, 2013, p. 113).

Ou seja, o modo de regulação se trata de todo o complexo institucional que se amolda a um determinado regime de acumulação, formando assim um determinado modelo de desenvolvimento - por exemplo, o Fordismo ou o Pós-fordismo.

Vale apontar que o Estado se trata do núcleo central do modo de regulação, assim como este se compõe, também, por todo o sistema jurídico. E é por isto que de tempos em tempos o aparato legal se modifica, ora se apresentando mais social, ora se apresentando ainda mais explorador. A exceção, conforme já apontado, é o núcleo mínimo fundamental necessário à reprodução do capital, e que por isto se mostra estável.

\footnotetext{
${ }^{2}$ Vale apontar que este entendimento se trata de uma leitura empreendida pelos teóricos derivacionistas, em especial os citados, das Escolas da Regulação. Esta foi inaugurada na França, na década de 1970, pelo teórico Michel Aglietta e, embora partindo da tradição crítica, tomou rumos diversos, inclusive se distanciando desta perspectiva. Hirsch e Mascaro resgataram os conceitos regulacionistas e, ao perceberem que os arranjos gerados pela dinâmica entre regime de acumulação e modo de regulação passam necessariamente pelas formas de sociabilidade elementares na reprodução capitalista, quais sejam, forma mercadoria, forma política estatal e forma jurídica, empreenderam a sua mais avançada leitura.
}

Em Debat: Rev. Dig., ISSNe 1980-3532, Florianópolis, n. 9, p. 23-39, jan-jun, 2013. 
Dito isto, resta ainda tratar de uma questão fundamental no que diz respeito à legalidade. Foi visto que a legalidade surge com a ascensão burguesa e a formação do Estado de Direito, e se trata do governo das leis. Porém, há que se responder como se explicam, então, os regimes autoritários, ou seja, de suspensão da lei.

Primeiro, há que se ter em mente que os regimes de governo também fazem parte do modo de regulação, e que portanto se estabelecem em determinado momento em conformidade com um regime de acumulação. É por isto que se modificam, de tempos em tempos, tal como veremos de perto no exame do caso brasileiro.

Além disto, há que se destacar especialmente que, ainda que não se governe a partir das leis, em um regime de exceção sempre haverá o núcleo mínimo de direito fundamental à própria reprodução capitalista, conforme se procurou ressaltar. E isto porque as leis da esfera política se diferem das leis da esfera civil, aonde se encontra este núcleo mínimo de direitos essenciais à reprodução capitalista - liberdade e igualdade jurídicas, propriedade privada e cumprimento de contratos. Até porque, vale lembrar que o direito deve ser compreendido como norma social, isto é, os elementos econômicos necessários à reprodução do capital se materializam na reprodução antes de se albergarem em algum aparato normativo criado pelo Estado.

Ademais, ainda que para a sua reprodução dependam que o Estado os assegure, inversamente, o Estado, independentemente das regras adotadas na esfera política - se democráticas ou não - também precisa que as relações sociais de produção se reproduzam para a própria sustentação. E isto porque a forma política estatal é um elemento específico e parte inerente ao modo de produção capitalista, e, na medida em que não há a reprodução do capital, o próprio Estado se esvai (HIRSCH, 2010; MASCARO, 2013).

Ou seja, o conjunto de direitos fundamentais à reprodução do capital será sempre assegurado, independentemente do regime de governo se basear ou não na legalidade. Apesar disto, a democracia é, de fato, um regime preferível em relação a governos autoritários. Conforme aponta Caldas,

Nota-se que ela (a legalidade) é somente defendida pelos liberais na medida em que não coloca em risco a manutenção das próprias relações sociais capitalistas. Noutras palavras, a alternância de governantes é tolerante conquanto que os fundamentos da economia capitalista não corram risco. Em todos os países nos quais o governo foi conquistado, democraticamente, por forças políticas contrárias ao capitalismo, os pensadores liberais, as forças políticas de direita, imediatamente defenderam a quebra da legalidade como forma de garantir a

Em Debat: Rev. Dig., ISSNe 1980-3532, Florianópolis, n. 9, p. 23-39, jan-jun, 2013. 
"manutenção da ordem", leia-se, ordem capitalista (...) Porém, ainda que a quebra da legalidade pela burguesia seja preferível em casos extremos, ela não é desejável, pois a supressão parcial do Estado de Direito implica a diminuição das condições ideais de reprodução das relações sociais capitalistas (pois afeta a segurança jurídica). Noutras palavras, as ditaduras de direita são sempre uma opção para a burguesia, mas não a melhor (CALDAS, 2014, p. 78-9).

É em função desta necessária estabilidade, aliás, que mesmo em um regime de exceção se busca certa segurança jurídica. Neste sentido já apontou Agamben que "o estado de necessidade tende a ser incluído na ordem jurídica e a apresentar-se como o verdadeiro 'estado da lei" (AGAMBEN, 2004, p. 43). De fato, vale lembrar que foi assim que se apresentou o Regime Militar brasileiro, que buscou encobrir seu caráter de exceção por meio de eleições periódicas e funcionamento quase ininterrupto do Congresso Nacional.

Dito isto, já é possível se passar, enfim, à análise propriamente do cenário brasileiro na transição para o pós-fordismo.

\section{Pós-fordismo, legalidade e direito no Brasil}

Vistos os elementos estruturais do capitalismo, que permitiram uma melhor compreensão do próprio direito e da legalidade, bem com as categorias intermediárias, tal como regime de acumulação e modo de regulação, que permitem uma verificar a razão das transformações que se operam no modo de produção capitalista, cabe agora examinar o panorama brasileiro a partir de sua transição para o pós-fordismo, analisando-se as mudanças operadas no direito e na legalidade em função deste contexto. Para tanto, se verificará inicialmente os principais aspectos do fordismo e pós-fordismo, para após passar a se compreender este cenário de mudanças especificamente no Brasil.

O fordismo foi um modelo de desenvolvimento que se consolidou a partir da segunda metade do século XX e se desenvolveu sob o poder hegemônico estadunidense, que financiou a reconstrução dos países no pós-guerra e estimulou por meio de empréstimos as economias do bloco capitalista, inclusive dos países periféricos como o Brasil.

Ainda que guardadas as especificidades de cada país, pode-se apontar como características centrais do fordismo: i) um regime de acumulação baseado no modo de produção taylorista, método de organização de trabalho que, por meio de uma 
racionalização no setor produtivo buscou aumentar sua eficiência, revolucionando todos os processos econômicos e ii) um modo de regulação de inspiração keynesiana, também chamado de monopolístico, devido à proeminência da atuação estatal, que promovia fomentos ao investimento, formação de infraestrutura, etc. além da mediação dos conflitos de classe e um programa de concessões sociais, distribuição de renda, controle salarial, etc., que se deu com o fortalecimento da classe trabalhadora diante do aumento da produtividade.

Porém, o funcionamento do sistema monetário internacional baseado no padrão dólar-ouro aliado à aceleração econômica no cenário global passou a gerar problemas para o governo norte-americano ainda na década de 1960: a alta emissão da moeda levou a um cenário de inflação, que, pressionando por uma desvalorização do dólar, prejudicaria a economia interna dos Estados Unidos e sua política hegemônica. Tal situação foi resolvida com o rompimento unilateral do acordo de Bretton Woods em 1971, que desatrelou o dólar do ouro gerando tumulto no sistema monetário internacional. A saída dos Estados Unidos para a manutenção da hegemonia da moeda norte-americana como meio de pagamento internacional veio com a elevação da taxa de juros em 1979, que logo retomou a força do dólar (PAULANI, 2008, p. 111-3).

O resultado disto no contexto global foi crise fiscal nos países endividados externamente - tal como o Brasil - e alta da inflação, situação que se agravou ainda pelas crises do petróleo da década de 1970 (idem). E uma vez que o cenário de crise do fordismo já estava instaurado, um novo regime de acumulação se colocava em movimento.

Isto ocorreu com o próprio rompimento do padrão dólar-ouro, que promoveu uma dinâmica desenfreada do crédito monetário e especulações na taxa de cambio, dando início a um novo regime de acumulação, desta vez baseado em um capital financeiro internacionalizado (MASCARO, 2013, p. 112-27).

Assim, para amparar esta nova dinâmica na economia, outro complexo institucional vai dar lugar ao antigo modelo keynesiano. O modo de regulação passa a se basear em políticas de taxação dos fluxos especulativos e medidas de liberalização financeira dos mercados, a fim de atrair a entrada de capitais. E isto porque

O modo de acumulação do capitalismo, que funcionara no período anterior (anos dourados), não se adequava mais a um regime de acumulação que funcionava agora sob o império da valorização financeira. Volátil por natureza, logicamente 
desconectado da produção efetiva de riqueza material da sociedade, curto-prazista e rentista, o capital financeiro só funciona adequadamente se tiver liberdade de ir e vir, se não tiver de enfrentar, a cada passo de sua peregrinação à procura de valorização, regulamentos, normas e regras que limitem seus movimentos (PAULANI, 2008, p. 116).

É o advento da matriz político-econômica neoliberal, inspirada em teóricos como Friedrich Hayek e Milton Friedman. E, apesar do discurso neoliberal defender uma política de um Estado mínimo, uma vez que a forma política estatal é imprescindível para a reprodução do capital, conforme visto, não há uma retirada do Estado de cena:

\begin{abstract}
Ainda que as decisões de investimento sejam descoladas dos Estados para o capital internacional (...) os Estados continuam a conformar e a garantir a dinâmica do capital. As garantias das propriedades, dos contratos, a exigibilidade dos vínculos jurídicos ou a necessidade da garantia da ordem interna para o desenvolvimento do capital, por exemplo, se mantêm e, na verdade, se exponenciam nas condições contemporâneas do capitalismo. A atual perda relativa do poder econômico dos Estados se faz acompanhar de um pleito do capital por segurança jurídica e força policial desses mesmos Estados, como forma de garantia de sua própria reprodução (MASCARO, 2013, p. 106).
\end{abstract}

Ou seja, o que ocorre é a alteração da atuação do Estado, que se enfraquece como interventor da economia e promotor de direitos sociais para atuar fortemente na garantia de um espaço de valorização do capital financeiro por meio da promoção da ordem interna e segurança jurídica. Para tanto, o Estado irá modificar todo o seu aparato, inclusive legal, a fim de se ajustar às novas exigências do regime de acumulação. E é isto que ocorre no cenário brasileiro, com a ascensão do pós-fordismo, conforme se analisará a partir de agora:

Primeiro há que se apontar que, quando irrompe a crise mundial do fordismo, a partir da década de 1970, o país ainda se encontrava sob o mando ditatorial, em um regime de exceção jurídica instaurado ainda em 1964, quando os militares, aliados à burguesia industrial, derrubaram o governo Goulart após sua tentativa de empreender as Reformas de Base no país. Assim, por meio da implantação de uma política autoritária e repressiva, e apoiados pelos industriais brasileiros, os militares deram continuidade ao modelo desenvolvimentista de fomento à indústria que já vinha se desenvolvendo, típico do modelo fordista.

No que diz respeito aos direitos assegurados no governo militar, é interessante observar que, conforme aponta Carvalho, para compensar o esvaziamento dos direitos políticos e a supressão de direitos civis, o regime ditatorial investiu na promoção de direitos sociais - para assim conter os protestos populares -, implantando um plano de reforma previdenciária, com a criação do Instituto Nacional de Previdência Social e universalização Em Debat: Rev. Dig., ISSNe 1980-3532, Florianópolis, n. 9, p. 23-39, jan-jun, 2013. 
de direitos previdenciários, que pela primeira vez albergou os trabalhadores rurais e domésticos (CARVALHO, 2009, p. 170-2). Ademais, "para atender a exigência dos empresários, acabara com a estabilidade no emprego. Para compensar, foi criado em 1966 um Fundo de Garantia por Tempo de Serviço (FGTS), que funcionava como um segurodesemprego" (CARVALHO, 2009, P. 172).

Em face da aliança com a burguesia industrial nacional, ainda, o regime buscou promover o desenvolvimento do parque industrial brasileiro por meio de programas governamentais tais como os Planos Nacionais de Desenvolvimento - PND, embalados pelo slogan "Brasil Potência". Para financiar o desenvolvimento tecnologicamente dependente, porém, o país adquiriu inúmeros empréstimos com bancos internacionais, o que era facilitado pela baixa taxa de juros do período.

No entanto, com a crise do fordismo a partir da década de 1970, conforme visto, em face da quebra do sistema de Bretton Woods pelos Estados Unidos, crises do petróleo e o decorrente aumento da taxa de juros norte americano, em 1979, o país - juntamente com demais países da América Latina, que se viam em situação semelhante - se vê altamente endividado em uma crise fiscal sem precedentes. Com isto se instaurou um cenário de queda do PIB, aumento do desemprego e alta de inflação, que saltou para a esfera dos 200\% a partir de 1983 (PAULANI, 2006, p. 9).

A crise econômica no Brasil se refletiu, consequentemente, como perda de poder político do Regime Militar, impulsionando um movimento de redemocratização na década de 1980, embalado por crescentes manifestações populares, que vai desaguar na abertura democrática e na eleição do primeiro presidente civil, José Sarney, em 1985. O regime de exceção sofrido até então pelo país tinha chegado ao final.

O grande marco deste retorno democrático, sem dúvidas, foi a Constituição Federal de 1988, que, devido à ampla participação popular em sua elaboração - o que também incluiu lobbies de diferentes frações de classes da burguesia - logrou não só restaurar os direitos suprimidos no período ditatorial, mas ampliar os direitos civis, políticos, sociais, culturais, etc., consagrando-a como a "Constituição Cidadã”.

Assim, a nova Carta trouxe uma importante gama de direitos sociais, podendo-se destacar a implantação do Sistema Único de Saúde - SUS e o avanço do sistema de 
seguridade social, que baseado no princípio da solidariedade e na universalidade de atendimento, foi implantado sob concepção extremamente avançada.

No entanto, apesar deste amplo rol de direitos constitucionalizados, o país ainda se encontrava economicamente fragilizado, o que inviabilizou a promoção de políticas públicas para implantá-lo. E em função da crise, passou a se instaurar no lugar do regime de exceção jurídica do período militar, o que a economista Leda Paulani chama de "estado de emergência econômico" (PAULANI, 2006).

E isto porque, para conter a crise, já no primeiro governo civil utilizou-se do artifício do decreto-lei para implantar o Plano Cruzado. Porém, conforme aponta Paulani,

Como parecia de fato haver uma ameaça real de desorganização das cadeias de produção e da vida material do país, além do prejuízo imposto às classes mais baixas, qualquer solução era admitida, mesmo que infringisse as regras jurídicas e de ordenação dos poderes (PAULANI, 2006, p. 11).

Com o colapso do plano econômico, o governo, que ainda buscava manter a política desenvolvimentista, passou a ser duramente atacado, sobretudo em face do avanço neoliberal, que tomou impulso como discurso único com o colapso da União Soviética.

E é com este discurso, de ineficiência estatal e liberdade do mercado, baseado em economistas como Milton Friedman e Friedrich Hayek, que Collor vence as eleições de 1990. No entanto, em face de seus laços políticos e curto mandato, que durou até 1992, não foi conseguiu a implantação da agenda neoliberal, o que só viria a se realizar nos governos seguintes.

No governo Itamar Franco (1992-1994), conseguiu-se enfim estabilizar a inflação, a partir da implantação pelo então Ministro da Fazenda Fernando Henrique Cardoso do Plano Real. Conforme aponta Paulani, este consistiu na "securitização da dívida e internacionalização do mercado brasileiro de títulos da dívida pública, além da liberalização do fluxo internacional de capitais" (PAULANI, 2006, p. 12). Aqui se iniciava a aliança com o capital financeiro internacionalizado, em detrimento da burguesia industrial nacional.

E de acordo com Paulani, ainda, em meio a estas negociações de abertura do mercado brasileiro, o Banco Central

Encarregava-se também, na surdina, de promover a desregulamentação do mercado financeiro brasileiro e a abertura do fluxo internacional de capitais. A partir de mudanças operadas nas chamadas contas CC5 - contas exclusivas para não residentes, que permitiam, graças a uma lei de 1962, a livre disposição de recursos em divisas - o Bacen abriu a possibilidade de qualquer agente,

Em Debat: Rev. Dig., ISSNe 1980-3532, Florianópolis, n. 9, p. 23-39, jan-jun, 2013. 
independentemente de ser ou não residente, enviar livremente recursos ao exterior, bastando, para tanto, depositar moeda doméstica na conta de uma instituição financeira (PAULANI, 2006, p 13-4.).

O problema é que, conforme enfatiza a autora, "essa transformação foi feita de modo completamente irregular, pois uma lei federal não pode ser regulamentada por um órgão de hierarquia constitucional inferior. Em outras palavras, o Congresso teria de ser ouvido e não foi" (PAULANI, 2006, p. 14). E é aí que se encontra o "estado de emergência econômico", já que "a medida, absolutamente irregular do ponto de vista jurídico, se auto justificou em função da necessidade de modernizar o mercado financeiro brasileiro através de sua desregulamentação" (idem).

Com a eleição de Fernando Henrique Cardoso (1995-2002), a implantação da agenda neoliberal tomou força, o que se justifica especialmente pelo acordo de renegociação da dívida implantado ainda na gestão anterior, em que, vale lembrar, FHC era o Ministro da Fazenda. Conforme aponta Harvey,

As instituições financeiras concordaram em contabilizar como perdas $35 \%$ do principal de dívidas de que eram credoras em troca do desconto de títulos (com o apoio do FMI e do Tesouro dos Estados Unidos), tendo garantido o pagamento do restante (ou seja, garantiu-se aos credores o pagamento de dívidas à taxa de 65 centavos por dólar). Por volta de 1994, cerca de 18 países (como México, Brasil, Argentina, Venezuela e Uruguai) aceitaram acordos que previam o perdão de 60 bilhões de dólares de suas dívidas. Naturalmente, tinham a esperança de que esse alívio da dívida iria provocar uma recuperação econômica que lhes permitiria pagar num momento oportuno o resto da dívida. O problema estava no fato de o FMI ter imposto aos países que aceitaram esse pequeno perdão da dívida (quer dizer, pequeno em relação ao que os bancos poderiam ter concedido) que engolissem a pílula envenenada das reformas institucionais neoliberais" (HARVEY, 2012, p. 85).

Assim, as reformas neoliberais no Brasil tomam impulso, e, para tanto, o discurso de "estado de emergência econômico" também. Conforme aponta Paulani, sob a justificativa de inúmeras "ameaças" (retorno da inflação, da perda de credibilidade, do desequilíbrio fiscal, do atraso, de desvalorização da moeda, etc), e até, da "perda do bonde da história", inúmeras medidas foram implantadas por FHC, tais como a elevação da taxa real de juros a níveis alarmantes - que chegaram ao pico de 40\% -, abertura desenfreada da economia - que levou à quebra da indústria nacional -, privatização de empresas públicas atuantes em setores estratégicos da economia, e a tão criticada Lei de Responsabilidade Fiscal (Lei Complementar $n^{0}$ 101, de 2000), também conhecida como "Lei de Irresponsabilidade Social". 
Isto porque, com a promulgação da LRF, os direitos dos credores foram colocados acima de quaisquer outros direitos, além de inviabilizar a promoção de direitos assegurados pela Constituição Federal, na medida em que esgotou a capacidade econômica de intervenção estatal em prol de uma estabilização monetária "necessária" à economia ${ }^{3}$. A este respeito, conforme apontam Bercovici \& Massonetto,

Após 1988, o controle do orçamento monetário provocou a subordinação das políticas fiscais (e do "orçamento-programa") à política de estabilização monetária. (...) A ordem econômica e dirigente da Constituição de 1988 é isolada de seus instrumentos financeiros, cuja efetividade é medida em si mesma, sem qualquer relação com os objetivos da política econômica estatal ou da ordem econômica constitucional. A Lei de Responsabilidade Fiscal e a insana emenda constitucional instituindo o déficit nominal zero são os meios de excluir o orçamento da deliberação pública, garantindo metas de política monetária muitas vezes impostas de fora e em favor de interesses econômicos privados, que desejam uma garantia sem risco para seus investimentos ou para sua especulação financeira. A implementação da ordem econômica e da ordem social da Constituição de 1988, ficaram restritas, assim, às sobras orçamentárias e financeiras do Estado (BERCOVICI \& MASSONETTO, 2006, p. 16-70).

Paulani aponta que, para piorar o quadro, no governo Lula este estado de emergência econômica não se reverteu, pelo contrário: foi definitivamente decretado. Assim, mesmo em meio à normalidade da economia - taxa de câmbio valorizada, queda do risco país e valorização dos papéis brasileiros nas bolsas internacionais - Lula promoveu medidas como a manutenção da taxa de juros a níveis alarmantes, em evidente benefício da valorização do capital rentista; a promulgação da Lei 10.820/2003, que autorizou desconto na folha de pagamentos do trabalhador relativos à empréstimos e financiamentos, em descumprimento direto do artigo 462 da Consolidação das Leis Trabalhistas (CLT), que consagra o princípio da intangibilidade salarial; a promulgação da Lei de Falências, que prioriza os interesses dos credores do sistema financeiro ao colocá-los à frente dos interesses dos trabalhadores e do próprio Estado no gerenciamento da massa falida e a reforma do sistema previdenciário, em que acabou com o solidarismo intergeracional.

Assim, em que pese a redemocratização e a ampla gama de direitos trazidos pela Constituição Federal, sob o mote de um estado de emergência econômico, proclamado pelas necessidades do capital financeiro, se passou por cima de inúmeros direitos fundamentais. Para o jurista Paulo Bonavides, estas inúmeras reformas fizeram o país

\footnotetext{
${ }^{3}$ Vale dizer que, conforme aponta Bercovici \& Massonetto, a Lei de Responsabilidade Fiscal faz parte de um processo de centralização financeira e orçamentária iniciada ainda na década de 1970 e que, em última instância, foi responsável por uma "blindagem" à Constituição Econômica brasileira de 1988 (BERCOVICI \& MASSONETTO, 2006).
}

Em Debat: Rev. Dig., ISSNe 1980-3532, Florianópolis, n. 9, p. 23-39, jan-jun, 2013. 
passar do status de País constitucional para país neocolonial. Vale a pena reproduzir as palavras do autor:

Com o golpe de Estado institucional as instituições não mudam de nome; mudam, sim, de teor, substância e essência. De sorte que uma vez levado a cabo, a conseqüência fatal, no caso específico do Brasil, é a conversão do País constitucional ao País neocolonial. É também a perda da soberania, a desnacionalização, a desconstitucionalização (...) a legislação de medidas provisórias, a erosão e o desprezo dos princípios constitucionais, o alastramento da insegurança, do medo, da incerteza nas garantias da ordem jurídica (...) enfim o desfibramento daquela gente, que, ontem, foi povo e, hoje, é, tão-somente, triste e vegetativa multidão de servos submissos e vassalos genuflexos que o globalizador arrogante e sem escrúpulo esmagou com o braço de ferro do poder neoliberal (BONAVIDES, 2009, p. 24).

A necessidade de se assegurar o poder econômico mundializado permanece, e interfere "sempre que preciso" no plano legal. Por exemplo, com as inovações legislativas ocorridas em função da realização da Copa do Mundo e das Olimpíadas no Brasil. Conforme aponta Fernandes,

O governo federal, na intenção de flexibilizar as normas de licitação para a Copa do Mundo de Futebol de 2014 e Olimpíadas de 2016, editou as Medidas Provisórias 488 e 489. A primeira autorizava a criação da Empresa Brasileira de Legado Esportivo S.A. - BRASIL 2016, e a última previa a flexibilização dos procedimentos licitatórios para as contratações de obras relacionadas aos dois eventos esportivos.

As MPs 488 e 489, de 12 de maio de 2010, tiveram seu prazo de validade expirado no dia 22 de setembro do mesmo ano. Apesar de o governo concentrar seus esforços na aprovação dessas Medidas Provisórias, a estratégia da oposição em impedir a votação deu certo. Eles argumentavam que tais medidas eram oriundas da falta de organização do governo e que não faziam parte da agenda de prioridades da população.

O governo, que instituiu a criação da empresa Brasil 2016, por meio da extinta MP 488, manteve a criação da estatal com a edição do Decreto $n^{\circ} 7.258$, de 5 de agosto de 2010, que tinha o mesmo texto da referida Medida Provisória. Tal situação gerou uma série de críticas da oposição que afirmava ser inconstitucional a manobra do governo (FERNANDES, 2011, p. 38).

Além das medidas provisórias acima referidas, diversas outras foram criadas em função do evento esportivo: a MP 489, convertida na Lei 12.396/2011, referente ao regime de licitações para infraestrutura aeroportuária, a MP 521, que buscou instituir o Regime de Contratação Diferenciada (RCD), o que, conforme a oposição, deixaria lacunas para o superfaturamento de obras (FERNANDES, 2011, P. 45-6), etc.

Assim, conforme arremata Paulani, "Mesmo sem a decretação técnica de um estado de exceção, se faz tabula rasa da lei, sempre que os interesses materiais, embrulhados no discurso da necessidade posta pela emergência, se mostram mais poderosos que ela" (PAULANI, 2006, p. 15). Ou seja, quando se trata da reprodução das Em Debat: Rev. Dig., ISSNe 1980-3532, Florianópolis, n. 9, p. 23-39, jan-jun, 2013. 
relações socais capitalistas, a lei é proclamada pela necessidade econômica que se apresentar no momento.

\section{Conclusão}

$\mathrm{Na}$ primeira parte deste estudo se procurou demonstrar as formas estruturais do sistema capitalista, aonde se encontra um núcleo fundamental de direitos, imprescindível à reprodução do sistema: liberdade e igualdade jurídicas, propriedade privada e cumprimento de contratos. Estes direitos, enquanto houver capitalismo, sempre serão assegurados, independentemente de um regime democrático ou não.

Já na segunda parte desta análise percebeu-se que os demais direitos se modificam em conformidade com o regime de acumulação. Assim, no fordismo, se observou um amplo rol de direitos sociais favorável à própria proteção deste modelo de desenvolvimento, na medida em que era baseado em produtividade e necessitava, portanto, de um maior consenso de classe. No Brasil, conforme visto, este consenso foi assegurado por um regime de exceção jurídico - ou seja, o Regime Militar - que, a fim de apaziguar os ânimos da massa, concedeu uma gama de direitos sociais.

No entanto, com a ascensão do capital financeiro em detrimento do capital industrial, na passagem para o pós-fordismo, se alterou o modo de regulação e assim os direitos a serem assegurados pelo Estado. Apesar da Constituição Federal de 1988 proclamar uma extensa lista de direitos de cidadania, estes vão sendo gradativamente minados com a implantação da estrutura neoliberal, sob o mote de um pretenso estado de emergência econômico.

\section{Bibliografia}

AGAMBEN, Giorgio. Estado de Exceção. São Paulo: Boitempo, 2004.

BERCOVICI, Gilberto \& MASSONETTO, Luís Fernando. A Constituição Dirigente

Invertida. A blindagem da Constituição Financeira e a agonia da Constituição Econômica. In: Boletim de Ciências Econômicas XLIX, Coimbra, 2006. 
BONAVIDES, Paulo. Do país constitucional ao país neocolonial. A derrubada da Constituição e a recolonização pelo golpe de Estado institucional. $4^{a}$ Ed. São Paulo: Malheiros, 2009.

BOYER, Robert. Teoria da Regulação: os fundamentos. São Paulo: Estação Liberdade, 2009.

CALDAS, Camilo Onoda. O Estado. São Paulo: Estúdio Editores, 2014.

CARVALHO, José Murilo de. Cidadania no Brasil. O longo Caminho. 12a Ed. Rio de Janeiro: Civilização Brasileira, 2009.

FERNANDES, André Bittencourt de Aquino. Licitação. Inovações legislativas para a Copa do Mundo de 2014. Monografia. UniCEUB, 2011.

HARVEY, David. O neoliberalismo: história e implicações. $3^{\text {a }}$ Ed. São Paulo: Loyola, 2012.

HIRSCH, Joachin. Teoria Materialista do Estado. Rio de Janeiro: Revan, 2010.

MASCARO, Alysson Leandro. Crítica da Legalidade e do Direito Brasileiro. $2^{\mathrm{a}}$ Ed. São Paulo: Quartier Latin, 2008.

Estado e forma política. São Paulo: Boitempo, 2013.

NAVES, Márcio Bilharinho. Marxismo e Direito: um estudo sobre Pachukanis. São Paulo: Boitempo, 2008.

PAULANI, Leda. Brasil Delivery. São Paulo: Boitempo, 2008.

Capitalismo financeiro e estado de emergência no Brasil: o abandono da perspectiva do desenvolvimento. In: I Colóquio da Sociedade Latino Americana de Economia Política e Pensamento Crítico, 2006, Santiago, 2006. 